\title{
Flexural Creep of Steel Fiber Reinforced Concrete in the Cracked State
}

\author{
E. García-Taengua*, S. Arango, J.R. Martí-Vargas, P.Serna \\ ICITECH - Institute of Concrete Science and Technology \\ Universitat Politècnica de València, 4G Bldg., Camí de Vera s/n 46022 Valencia (Spain) \\ e-mail addresses: emgartae@upv.es, samo_59@hotmail.com,jrmarti@cst.upv.es, \\ pserna@cst.upv.es
}

*Corresponding author: emgartae@upv.es (E.García-Taengua)

\begin{abstract}
:
This paper aims at assessing the effect of a number of variables on flexural creep of steel fiber reinforced concrete in its cracked state, namely: fiber geometry (slenderness and length), fiber content, concrete compressive strength, maximum aggregate size, and flexural load. Notched prismatic specimens have been subjected to sustained flexural loads for 90 days following a test setup and methodology developed by the authors. Several experimental outputs have been measured: initial crack width, crack width at 90 days, and crack opening rates and creep coefficients at 14, 30, and 90 days. Multiple linear regression has been applied to relate these creep parameters to the variables considered. Semi-empirical equations have been obtained for these parameters. Statistical inference has been applied to identify the variables that have a statistically significant effect on SFRC flexural creep response. Fiber slenderness and fiber content have been found to significantly modify the effect that load ratio has on flexural creep response of SFRC.
\end{abstract}

\section{KEYWORDS:}

bending, concrete, creep, cracked state, steel fiber, test 


\section{INTRODUCTION}

The evolution of strains and crack openings through time is fundamental for the durability of concrete structures. Time-dependent phenomena such as shrinkage and creep must be taken into account besides instantaneous strains and cracking $[1,2]$.

Creep refers to the tendency of materials to develop increasing strains through time when they are subjected to a sustained load. As a result, deflection or elongation values tend to increase through time in relation to the initial strain, i.e. right after the load is applied. Codes for structural concrete consider compressive creep of concrete within the usual ranges in service conditions. On the contrary, tensile creep of either concrete or reinforcing bars is not usually considered. However, in the case of concrete structures, their long-term performance is basically affected by the behavior of cracked concrete [3].

Steel Fiber Reinforced Concrete (SFRC hereafter) members are designed in most applications to take advantage of SFRC differential features with respect to conventional concrete: when SFRC is brought to perform in the cracked state, cracks are under control and residual strength provides the structural member with further load-bearing capacity. There is no reason to expect differences between SFRC and conventional concrete regarding compressive creep. Any difference in terms of flexural creep behavior between SFRC and conventional concrete is related to the possibility of creep phenomena in the cracked zone of the section. Therefore the relationship between tensile creep and flexural creep of SFRC has attracted attention in recent studies [4]. Tensile creep of SFRC has been studied by some authors [5], but is not possible to easily extend their conclusions to flexural creep behavior. 
Flexural creep of SFRC in the cracked state and the role that different factors play in creep behavior are quite understudied topics within the general field of SFRC mechanical properties. There are relatively few publications directly related to flexural creep behavior of pre-cracked SFRC beams, and therefore every contribution is a step further [2]. The need of developments in the understanding of tensile and flexural creep behavior of SFRC is motivated by several purposes, mainly: to improve the prediction of cracking and the stress evaluation in prestressed members [6].

There is a considerable consensus in relation to the main sources of SFRC time-dependent flexural strains [7]: creep in the compression zone, time-dependent bond strains between concrete and fibers sewing cracks, and creep of the fibers material. However, there are some discrepancies among experimental results concerning the effect of fibers on tensile and flexural creep which call for further research, as observed by Garas et al. [8]. While several authors have found out that fibers reduce creep and shrinkage $[1,2,8,9]$, other studies have concluded that hooked-end steel fibers increase tensile creep [6].

Therefore, and considering that fibers contribution to load-bearing capacity is mainly related to flexural response in the cracked state, it is very important to evaluate how the material keeps crack opening values low enough so as to guarantee reinforcement effectiveness [10].

However, most of the studies on FRC flexural creep have compared the role of plastic or glass fibers to that of steel fibers, not focusing on the effect of steel fibers themselves. When some of these papers and reports $[10,11,12,13,14,15]$ are brought together, the following general aspects arise: 
- There is a variety of test setups and methodologies. Considering that SFRCs mechanical properties usually show considerable scatter, the lack of a standardized methodology contributes to uncertainty concerning SFRC creep behavior. An attempt to develop a consistent methodology based on a creep test setup for pre-cracked FRC specimens was needed.

- Most of the times the goal is not to characterize SFRC flexural creep but to compare the effect of steel fibers to that of synthetic fibers.

- Most studies limit their scope to one mix design, one type of steel fiber, or certain fiber content. In these cases, it is not considered how the variation of these parameters may affect SFRC creep behavior.

- In relation to the values considered for the stress/strength ratio, it is usual to consider different values. However, the way they are selected and the criteria this selection is based upon is not usually the same.

- There is an important heterogeneity concerning testing procedures and experimental approach. This leads to important differences between studies concerning several aspects, for instance: how load is applied to specimens, whether they are notched or not.

The aforementioned general aspects motivated two major goals for the research to be carried out. Firstly, to propose a general, standard-like methodology to study flexural creep of concrete. And second, to study the case of pre-cracked SFRC members in a comprehensive fashion, analyzing the effect of several parameters simultaneously. 
In relation to the first aspect, the authors have made an effort to develop a test setup and methodology which have been extensively described elsewhere [16]. The test setup and methodology proposed in [16] is susceptible of standardisation and can be used: a) to analyze crep behaviour under some given conditions (for a determined concrete mix design, load level, etc), and b) to characterize the effect of particular fiber types and/or dosages under standard conditions (materials, concrete mix design, fiber concrete, pre-cracking level, load). This way creep of concrete is studied in standard-like conditions so that future results can be easily compared. This is the methodology that has been followed in the experimental program reported herein. It is based on a structural test, where creep occurs in bending. This creep test has two major advantages: it is easier to perform and control than the direct tension test, and it can be directly correlated to the bending test as used for SFRC characterization (EN 14651). As compressive creep and tensile creep can occur simultaneously in the section, results may be affected by creep in the compressed zone of mid-span section if the derived peak compressive stress is close to concrete compressive strength. As a result, it is not easy to dissemble the contributions of both phenomena on flexural creep. In spite of this, further developments in the interpretation of the phenomena converging in flexural creep response as obtained from this test are very interesting, as well as their possible implementation in codes, but these aspects fall out of the scope of this paper.

\section{OBJECTIVES AND SCOPE}

The major purpose of this research was to analyze the effect that different variables have on SFRC response to sustained flexural loads in the cracked state. 
These variables have been selected to represent both SFRC composition and the load applied. Accordingly, different types of hooked-end steel fibers (in terms of length and slenderness), fiber contents, and concrete mix designs have been considered. A number of prismatic specimens have been produced and subjected to different sustained flexural loads covering usual values of these parameters in real applications.

Several creep parameters have been analyzed. The analysis of experimental results has followed a rigorous, statistical approach to assess the significance of the variables considered. The result is therefore a unified perspective on the relative contribution of the variables considered to flexural creep response of SFRC in the cracked state. This perspective offers a further conceptualization of the phenomenon under study.

\section{METHODOLOGY AND EXPERIMENTAL OUTPUTS}

\subsection{The Creep Test}

Prismatic 150x150x600 mm specimens have been produced, notched, pre-cracked, and then tested under flexural loads sustained for 90 days in agreement with the creep test setup and methodology developed by the authors [16]. An overview of this methodology is given in Fig. 1.

In a first stage, specimens are pre-cracked: each specimen is notched and loaded according to a four-point scheme based on the standard bending test [17, 18], with a $450 \mathrm{~mm}$ span between supports, until a crack mouth opening displacement (CMOD hereafter) of $0.50 \mathrm{~mm}$ is reached. 
The load corresponding to this crack width, Fw, is retained and the specimen is then totally unloaded.

Pre-cracked specimens are reloaded and subjected to sustained load conditions according to the test setup shown in Fig. 2 (for dimensions and further details see [16]). Specimens are tested in columns of three to rationalize the requirements of time and space. The creep frame and all its components, in particular loading members and supports, have been conceived to be stiff enough to avoid undesirable, abrupt movements as well as friction in supports in order not to interfere the development of creep strains. This, together with the gravity loading on top of the specimens column (by means of a counterweight applied through a lever arm), guarantees the application of a constant load. This way all three specimens are loaded according to the four-point bending test and the load is kept constant for a determined lapse of time. In the case of this research, this timespan was 90 days, since the largest part of timedependent strains occurs within the first two months [6].

The creep test ends after 90 days, when specimens are unloaded and elastic deformation is recovered. Thereafter each specimen is subjected to a complete bending test until failure to characterize the flexural response of the material in the cracked state.

Any other conditions (namely humidity and temperature) are kept constant throughout the testing process (for further details see [16] and [18]). An appropriate set of measurement devices have been used to quantify and monitor CMOD values regularly. Crack opening was monitored instead of deflection because CMOD values have been reported to be more sensitive to the number of fibers than mid-span deflection values (most recently [1]). Some examples of the evolution of CMOD values vs time can be found in [16]. 
In addition to prismatic specimens for the creep test, all batches of concrete were characterized by assessing their flexural response and compressive strength.

\subsection{Definition of Response Parameters}

According to the general testing procedure described in the previous section, the complete process for each specimen leads to a flexural load vs CMOD curve, as the idealized one shown in Fig. 3 for illustration purposes.

The first part of the curve corresponds to the pre-cracking stage. There is an ascending linear branch until the first crack occurs (A). The specimen is gradually loaded until a crack width of $0.50 \mathrm{~mm}$ is reached (B), and then it is totally unloaded. Each specimen has been pre-cracked individually by being subjected to the 4-point bending test. After that, specimens have been transferred to the test setup shown in Fig. 2 and subjected to the creep test.

The creep test as such begins at point $(\mathrm{C})$ : the ascending line (CD) corresponds to the loading process, which is followed by a horizontal branch (DE) corresponding to the increasing deferred deformations (load sustained through time). This horizontal line ends up when the specimen is unloaded 90 days afterwards $(\mathrm{EF})$. 
Finally, the specimen is subjected to the four-point bending test, which is represented by the third region of the plot: it begins with an ascending line (FG) and continues with the residual performance curve of the specimen (GH).

Several parameters are obtained from the load-CMOD curve to characterize the response of each specimen under sustained flexural load. These parameters constitute the outputs of the experimental program. Therefore, the analysis of experimental results is focused on the values of these creep parameters. They can be grouped as follows:

- Recovery ratio, $\mathrm{r}$, is related to the pre-cracking stage. It measures the recovery of strains right after pre-cracking. It is defined by Equation (1), where: $\mathrm{w}_{\mathrm{p}}$ is the maximum CMOD reached when pre-cracking the specimen (namely $0.5 \mathrm{~mm}$ ), and $\mathrm{w}_{\mathrm{pr}}$ is the residual CMOD when the specimen is unloaded after pre-cracking.

$$
r=\frac{w_{p}-w_{p r}}{w_{p}}
$$

- Untransformed data regarding the material's strains: $\mathrm{w}_{\mathrm{ci}}$, the CMOD value at the beginning of the creep test, measured one minute after the load has been applied; and $\mathrm{w}_{\mathrm{cd}}(90)$, the CMOD value measured 90 days after the load was applied, retained as representative of the delayed, accumulated creep strains.

- Crack opening rates $\operatorname{COR}\left(\mathrm{t}_{1}-\mathrm{t}_{2}\right)$ for different time periods, evaluated as the ratio between the increase in crack opening and the lapse of time from $t_{1}$ until $t_{2}$. Three crack opening ratios have been considered: $\operatorname{COR}(0-14), \operatorname{COR}(14-30)$ and $\operatorname{COR}(30-90)$.

- Specific crack opening rates $\operatorname{spCOR}\left(\mathrm{t}_{1}-\mathrm{t}_{2}\right)$ : $\operatorname{spCOR}(0-14), \operatorname{spCOR}(14-30)$, and $\operatorname{spCOR}(30-90)$, are defined as the corresponding crack opening rate typified by the equivalent flexural tensile stress corresponding to the flexural load that is applied. 
- Creep coefficients $\varphi(j)$ are defined at different $\mathrm{j}$ times as the ratio between the deferred crack opening at time $j, \omega_{c d}(j)$, and the initial crack opening at the beginning of the creep stage, $\mathrm{w}_{\mathrm{ci}}$. In the case of this research the creep coefficients analyzed are $\varphi(14)$, $\varphi(30), \varphi(90)$, i.e. at 14,30 , and 90 days, respectively.

- Creep coefficients referred to the origin $\varphi_{\mathrm{o}}(\mathrm{j})$ are evaluated as the ratio between the deferred crack opening at time $j, w_{c d}(j)$, and the crack opening at the beginning of the creep test in the complete curve, which is $\mathrm{w}_{\mathrm{pr}}+\mathrm{w}_{\mathrm{ci}}$. Three creep coefficients referred to the origin, $\varphi_{\mathrm{o}}(14), \varphi_{\mathrm{o}}(30)$, and $\varphi_{\mathrm{o}}(90)$ have been considered, at times of 14,30 , and 90 days respectively.

\section{EXPERIMENTAL PROGRAM AND RESULTS}

\subsection{Selection of Variables and Levels}

Table 1 summarizes the variables and the different levels considered for them, selected according to the criteria discussed in the following paragraphs.

Several different concrete mixes have been produced. Each particular concrete mix results from slightly modifying one of the so-called 'base' mix designs, adjusted to include different fiber contents. Two different base mix designs have been considered corresponding to specified compressive strength $\left(\mathrm{f}_{\mathrm{c}}\right)$ values of $25 \mathrm{MPa}$ and $40 \mathrm{MPa}$, hence covering the range of low and mid-strength concretes. The maximum aggregate size is $10 \mathrm{~mm}$ for all $40-\mathrm{MPa}$ mixes, and $20 \mathrm{~mm}$ for $25-\mathrm{MPa}$ mixes with with the exception of some batches that were adjusted to a maximum aggregate size of $10 \mathrm{~mm}$. Accordingly, maximum aggregate size has also been a variable. This was convenient because it might have an effect on creep strains: 
aggregates are known to behave elastically while the paste fraction of concrete is the primary agent of time-dependent strains [9].

Five different steel fibers have been considered: both fiber slenderness ( $\square_{\mathrm{f}}$ ) and fiber length $\left(\mathrm{L}_{\mathrm{f}}\right)$ have been considered as variables. Fiber contents $\left(\mathrm{C}_{\mathrm{f}}\right)$ used are $40 \mathrm{~kg} / \mathrm{m}^{3}$ and $70 \mathrm{~kg} / \mathrm{m}^{3}$, both below $1 \%$ in volume as it is the most usual case in most of the applications where SFRC is used.

Load ratio is the variable which takes into account the flexural load that has been applied and sustained. The nominal load ratio (IFn) is defined as the ratio between the load that is applied to the specimen at the top and the load corresponding to a CMOD of $0.50 \mathrm{~mm}$ in the precracking stage, Fw, in percentage. However, the applied load ratio (IFa) is not directly IFn: different specimens from the same batch are never identical and, since they are tested in columns of three (see Fig. 1), the specimen at the bottom bears a slightly higher load than the one at the top. Therefore the applied load ratio (IFa) differs from the other variables considered: this is not a variable that could be pre-fixed at certain values. IFn has been considered at $60 \%$ and $80 \%$, so that the range of load ratios selected by other authors is covered: $50 \%$ in the case of $[1,6]$, and between $76 \%$ and $92 \%$ in the case of [3]. However, for the analysis of results IFa values (ranging from $54.2 \%$ to $97.2 \%$ ) are considered instead of IFn, since they represent more exactly the loading applied to each particular specimen.

Taking all that into consideration, the relative position of a specimen in each group of three might somehow affect the results. This is the reason why this relative position has been considered as one more variable, so that its effect on creep parameters, whenever present, could be detected and properly attributed instead of confounding the effects of other variables. 
As it is derived from Fig. 2, there are three different positions: 1 for the top, 2 for the middle, and 3 for the bottom.

Table 2 summarizes all specimens produced and tested in this research as combinations of the variables considered. Each set of three specimens listed consecutively in Table 2 corresponds to the same batch.

\subsection{Experimental Results}

The specimens tested in this research have shown residual strength $f_{R 1}$ values (corresponding to CMOD of $0.5 \mathrm{~mm}$ ) ranging from 3.69 to $10.19 \mathrm{MPa}$. Therefore these SFRC mixes can be referred to as normal or high performance. Accordingly, the equivalent flexural stress applied in the creep test has ranged from 2.23 to $6.11 \mathrm{MPa}$. A kinematic analysis assuming plane strain state and rectangular distribution for tensile stresses in the concrete section reveals that peak compressive stress values are between $30 \%$ and $50 \%$ of concrete compressive strength. The aforementioned values have been given only for informative purposes and they set the ground for different approaches to the analysis of SFRC flexural creep behavior, being out of the scope of this paper. The analyses reported herein are focused on the response parameters which have been defined in a previous section.

Values obtained for the response parameters are extensively reported. Table 3 presents the complete dataset of experimental results obtained from the pre-cracking stage $\left(\mathrm{r}, \mathrm{w}_{\mathrm{ci}}\right)$ and the 
creep test: $\mathrm{w}_{\mathrm{cd}}(90)$, crack opening rates, specific crack opening rates, creep coefficients and creep coefficients referred to the origin.

\section{ANALYSIS AND DISCUSSION}

\subsection{Overview of the Analysis}

The effects that the variables considered (Table 1) have on each one of the outputs of the experiment (creep parameters) have been assessed by means of multiple linear regression (MLR hereafter) [19]. The objective of MLR modelling is to relate each creep parameter to the variables considered. Then, statistical inference regarding the relative importance of each variable is evaluated by means of significance tests on the coefficients estimated in MLR modelling. To study separately the effect of each variable on creep parameters on the basis of one-to-one regression lines instead of MLR models would have been a defective approach: there would have been no possibility of evaluating their relative importance.

The aim of this research was not to arrive at a set of descriptive equations but to identify the variables that have a statistically significant effect on most of the creep parameters. Once identified, these key variables can be regarded as a general and therefore valuable conclusion. To do that successfully, MLR models must be conceived taking into account the conceptual basis of the phenomenon under study.

Fig. 4 summarizes the process that has been followed to analyze the experimental results obtained for creep parameters: 
1. The as-obtained dataset includes the values of all creep parameters for all specimens (Table 3).

2. Deletion of outliers: anomalous results or outliers are detected and cleared out from the results dataset. This has been performed by means of cluster analysis, namely the k-means algorithm [20]. Only one out of the thirty-one specimens tested has been discarded: data corresponding to specimen 30 in Table 3 are excluded. The clean dataset is subjected to statistical analysis in the following steps.

3. Analysis based on additive models: a first stage deals with fitting MLR models which relate each creep parameter to the simple effects of the variables considered.

4. Analysis based on semi-empirical models: a conceptual basis is searched for within the results of the previous step. New MLR models are developed for the creep parameters to include interactions between the variables in addition to their simple effects. These interactions are selected on the basis of previous knowledge: that is the reason why these models are called semi-empirical.

5. Interpretation: the results of previous analyses concerning the effects detected and their significance are put together and interpreted.

\subsection{Additive Models}

The so-called additive MLR models follow this general expression:

$$
c p_{i}=m_{0, i}+n_{i} I F a+m_{c, i} f_{c}+m_{a, i} M A S+\nabla_{f, i} C_{f}
$$

where: $c_{p i}$ stands for a certain creep parameter; IFa is the applied load ratio (in percentage); $f_{c}$ is the specified compressive strength of concrete (in MPa); MAS is the maximum aggregate size (in $\mathrm{mm}$ ); $\mathrm{m}_{0, \mathrm{i}}, \mathrm{n}_{\mathrm{i}}, \mathrm{m}_{\mathrm{c}, \mathrm{i}}$, and $\mathrm{m}_{\mathrm{a}, \mathrm{i}}$ are coefficients to be fitted; and $\mathrm{C}_{\mathrm{f}}$ is the fiber content (in 
$\mathrm{kg} / \mathrm{m}^{3}$ ), whose effect may vary depending on fiber geometry according to the following expression:

$$
\nabla_{f, i}=\nabla_{0, i}+\nabla_{\lambda, i} \lambda_{f}+\nabla_{L, i} L_{f}
$$

where: $\nabla_{0, i}, \nabla_{\lambda, i}$, and $\nabla_{L, i}$ are coefficients to be fitted; $\square_{\mathrm{f}}$ is fiber slenderness; and $\mathrm{L}_{\mathrm{f}}$ is fiber length (in $\mathrm{mm}$ ).

MLR models following this structure are called additive since they imply that the effect of the loading (given by the term $\mathrm{n}_{\mathrm{i}} \cdot \mathrm{IFa}$ in the equation) is simply added to that of the material (all other terms). Therefore each creep parameter is modelled as the sum of these two contributions.

For each creep parameter $\mathrm{c}_{\mathrm{pi}}$, coefficients $\mathrm{m}_{0, \mathrm{i}}, \mathrm{n}_{\mathrm{i}}, \mathrm{m}_{\mathrm{c}, \mathrm{i}}, \mathrm{m}_{\mathrm{a}, \mathrm{i}}, \nabla_{0, i}, \nabla_{\lambda, i}$, and $\nabla_{L, i}$ are estimated by least squares when the model is fitted to experimental data. Table 4 summarizes the results of significance tests on these coefficients. Each row in Table 4 corresponds to a creep parameter: each row summarizes a MLR analysis, R-squared values are given in the last column. Blank cells correspond to effects which are not statistically significant. In the case of significant effects, the sign of the estimated coefficient is given for interpretative purposes.

The process followed to come to MLR models as summarized by Table 4 has been stepwise regression [21]. The threshold considered for p-values identifying significant effects is 0.05 in all cases, which assumes a confidence level of $95 \%$.

There are differences among the creep parameters considered with respect to the variables that have a statistically significant effect on them. A very simple way of looking at the overall significance of each variable is counting the number of creep parameters on which this 
particular variable has a statistically significant effect. This 'count' is given in the last row of Table 4. It is clearly detected that fiber slenderness $\left(\square_{\mathrm{f}}\right)$ and load ratio (IFa) are the key parameters on flexural creep behavior.

The relative position of a specimen (Pos. in Table 4) in the creep test setup has turned out to be relevant concerning some of the creep parameters. The effect of this variable on creep parameters has been explored by means of box-and-whisker plots, shown in Fig. 5 and Fig. 6. A very similar tendency has been found for those creep parameters on which relative position has a significant effect. It is observed in Fig. 5, where each box stands for the interquartile length and the notches represent the 95\%-confidence interval for the mean in each case. Significant differences between position 3 and position 1 are observed, since their corresponding confidence intervals for the mean do not overlap. In the opinion of the authors, this is due to the different support and loading conditions under specimen 3 (at the bottom) with respect to specimens 1 and 2. For contrastive purposes, Fig. 6 shows box-and-whisker plots corresponding to a creep parameter on which position has no significant effect: all confidence intervals for the mean overlap.

The effect of fiber content is more important than it seems at first sight. First of all, the effect of fibers on creep behavior is somewhat covered by the effect of load ratio. It is worth recalling that load ratio, IFa, is the ratio between the applied load and Fw, which corresponds to $\mathrm{w}_{\mathrm{p}}$. Since $\mathrm{Fw}$ clearly depends on fiber content, the fact that load ratio is statistically significant means that fiber content is also significant, because residual load bearing capacity of concrete (and therefore $\mathrm{Fw}$ ) is increased with fiber content. 


\subsection{Semi-Empirical, Constitutive Models}

From the additive models summarized in Table 4 it follows that fiber slenderness $\left(\square_{\mathrm{f}}\right)$ and fiber content $\left(\mathrm{C}_{\mathrm{f}}\right)$, together with load ratio ( $\left.\mathrm{IFa}\right)$, are the capital factors influencing most of the creep parameters.

A further step in the analysis is concerned with MLR models which are rooted on the theoretical background of the phenomenon under study. Since they involve putting together this background and the experimental results, they have been called semi-empirical. This is an effort to interpret the statistical analysis of experimental results from a physical, mechanical perspective.

Other authors have previously underlined the convenience of approaching creep strains by means of empirical equations after the form of constitutive laws [6]. Considering that constitutive equations relate strain to stress, it has been decided to formulate semi-empirical MLR models where the creep parameter is related to the load ratio, IFa, whose effect is modified by the variables which are related to the material. As a result, MLR semi-empirical models follow this general expression:

$$
c p_{i}=m_{0, i}+\left(n_{i}+m_{c, i} f_{c}+m_{a, i} M A S+\nabla_{f, i} C_{f}\right) \cdot I F a
$$

where the term that multiplies IFa does not only relate to IFa itself (such standalone simple effect is represented by coefficient $\mathrm{n}_{\mathrm{i}}$ ) but is also affected by concrete compressive strength $\left(\mathrm{f}_{\mathrm{c}}\right)$, maximum aggregate size (MAS), and fibers geometry $\left(\nabla_{\mathrm{f}, \mathrm{i}}\right.$, as defined by equation (3)) and fiber content $\left(\mathrm{C}_{\mathrm{f}}\right)$. It is worth noting that assuming this formulation is similar to have results for all creep parameters typified by IFa. 
The process followed to come to MLR models that best fits experimental results and considers only statistically significant variables has been, as in the previous section, stepwise regression [21]. The threshold assumed for p-values identifying significant effects is 0.05 in all cases. Table 5 summarizes the significance tests for the semi-empirical MLR models.

Load ratio, IFa, has a standalone simple effect which is statistically significant on most of the creep parameters. This is clearly observed in Fig. 7, which shows creep coefficient $\varphi_{0}(90)$ versus IFa: $\varphi_{0}(90)$ clearly increases when load ratio is increased. The coefficient associated to this effect is positive in all cases, which is coherent with the fact that increasing load ratios lead to increasing crack widths, regardless of the particular creep parameter considered.

Specified concrete compressive strength significantly interacts with load ratio concerning some creep parameters. However, the coefficient corresponding to this interaction is positive in some cases and negative in some others: at this point it is not clear whether high concrete compressive strength directly implies higher creep strains or not.

Concerning fibers, all considerations given in the previous subsection can be recalled here. Fiber length does not interact with load ratio. On the contrary, fiber slenderness and fiber content clearly modify the effect of load ratio on flexural creep: the effect of their interaction with load ratio is statistically significant concerning several of the creep parameters considered.

The sign of the coefficient corresponding to the interaction between fiber content and load ratio is positive in all cases. This is clearly due to the following fact: the greater fiber content is, the higher the load bearing capacity. Therefore, for a given load ratio, the applied load will 
be higher when higher fiber contents are considered. As a result, this coefficient being positive does not mean that fibers increase creep strains for a certain load ratio. Rather, their presence makes the load applied higher for a given load ratio and therefore creep strains are increased.

On the other hand, the sign of the coefficient corresponding to the interaction between fiber slenderness, fiber content and load ratio is negative in all cases. This clearly indicates that the use of fibers with higher slenderness lessens the effect that high load ratios have on creep strains. In consequence, it can be said that the use of fibers is a good strategy in order to control creep strains and the best choice is clearly fibers with high slenderness.

\subsection{Comparison of additive and semi-empirical models}

The experimental results obtained from the creep test have been analyzed on the basis of two alternative perspectives in terms of MLR modelling: additive models, and semi-empirical, constitutive models. They point out to fiber slenderness $\left(\square_{f}\right)$ and fiber content $\left(\mathrm{C}_{\mathrm{f}}\right)$ together with the applied load ratio (IFa) as the most important variables to account for.

There are two key conclusions with respect to the role that fibers play in flexural creep. The first is that fiber length does not have a significant effect on flexural creep of SFRC (Tables 4 and 5). The second is that fiber slenderness has a statistically significant effect on most of the creep parameters, which is clearly detected in Tables 4 and 5. This is also observed in Figs. 8 and 9, which are given for illustration purposes. They show the box-and-whisker plots of $\operatorname{COR}(30-90)$ and $\varphi_{0}(90)$ respectively vs fiber slenderness, the notches representing the limits of $95 \%$-confidence intervals for the mean in each case. Both parameters tend to decrease 
when fiber slenderness is increased, a trend which has been detected to be statistically significant.

Both perspectives (additive models and constitutive models) have led to very similar conclusions, and this underlines the consistency of the conclusions reached. Furthermore they are totally coherent with one another in terms of the signs of the coefficients fitted for each. Therefore they constitute two alternative understandings of flexural behavior of SFRC:

- The additive models define each creep parameter as the result of directly adding the so-called material's contribution (endogenous sources: variables describing the fibers, the aggregates and the cementitious matrix) to the effect of the loading (exogenous source).

- Differently, the semi-empirical or constitutive models are conceived on a mechanistic basis: creep parameters are determined basically by load ratio, and the effect of load ratio is modified by material properties.

On the whole, the semi-empirical, constitutive MLR models do not improve the goodness of fit obtained with additive MLR models (compare Tables 4 and 5: the R-squared value is the same in 2 cases, is increased in 5 cases, and is decreased in 7 cases). This means that the semi-empirical, constitutive MLR models are not better than the additive MLR models if they are regarded as predictive equations. However, they represent a perspective on the phenomenon under study which is probably better justified from a physical point of view.

It is important to bear in mind that the purpose of this research was not to come to very accurate predictive equations, which is a different task because of the following reasons. First, 
the number of variables considered is rather high ( 7 variables) when compared to the number of tests performed (31 tests): the experimental program would have been more exhaustive if the authors had aimed at obtaining very accurate equations for predictive purposes. Second, SFRC flexural response shows a considerable scatter in the experimental results [22, 23], which is mainly dependent on the geometry of the fibers used and their dosage [1]. Third, the selection of creep parameters has been based on previous literature but they are probably susceptible of being reformulated and optimized in terms of their variability. The next step is obviously directed to obtain accurate predictive equations for different creep parameters which take into account the contribution of fibers in SFRC and towards a more stable definition of creep parameters. Such tasks are currently in progress, involving new experimental programs and the use of statistical multivariate techniques.

\section{CONCLUSIONS}

The experimental program carried out and the analysis of the creep test results by means of statistical techniques has made it possible to come to the following conclusions:

- The applied load ratio, IFa, has always a statistically significant effect on flexural creep response, and increasing the load ratio always leads to higher creep strains, regardless of the creep parameter considered.

- Fiber content and fiber slenderness together with load ratio determine flexural creep of precracked SFRC members.

- Fiber length does not have a statistically significant effect on the creep parameters analyzed.

- Fiber content has a statistically significant effect on most of the creep parameters considered. Increasing fiber content increases load bearing capacity and higher loads can be applied without increasing creep strains. 
- Increasing fiber slenderness leads to reduced creep strains. Furthermore, fiber slenderness has an important synergic effect with load ratio concerning the creep parameters considered: using fibers with high slenderness lessens the effect that load ratio has on creep strains.

- As a consequence, adding fibers is a good strategy in order to control creep strains and, though they are not required in high amounts, the best choice is to use fibers with high slenderness.

\section{REFERENCES}

[1] Buratti N, Mazzotti C. (2012) Effects of different types and dosages of fibers on the long-term behavior of fiber-reinforced self-compacting concrete. In: 8th RILEM International Symposium on Fiber Reinforced Concrete BEFIB 2012. Guimaraes, Portugal, pp. 177-178.

[2] Nakov D, Markovski G. (2012) Time dependant behavior of SFRC elements under sustained loads. In: 8th RILEM International Symposium on Fiber Reinforced Concrete BEFIB 2012. Guimaraes, Portugal, pp. 189-190.

[3] Barpi F, Valente S. (2002) Creep and fracture in concrete: a fractional order rate approach. Eng. Fract. Mech. 70(5):611-623.

[4] Mouton, C.J., Boshoff, W.P. (2012) Initial Study on the Tensile Creep of Cracked Steel Fibre Reinforced Concrete. In: 8th RILEM International Symposium on Fiber Reinforced Concrete BEFIB 2012. Guimaraes, Portugal, pp. 326-337.

[5] Zhao, G., Di Prisco, M., Vandewalle, L. (2012) Experimental research on uni-axial tensile creep behaviour of pre-cracked steel fiber reinfored concrete. In: 8th RILEM International Symposium on Fiber Reinforced Concrete BEFIB 2012. Guimaraes, Portugal, pp. 183-185 
[6] Bissonnette B, Pigeon M, Vaysburd M. (2007) Tensile Creep of Concrete: Study of Its Sensitivity to Basic Parameters. ACI Materials Journal 104(4):360-368.

[7] Kanstad T, Zirgulis G. (2012) Long-time creep testing of pre-cracked fiber reinforced concrete beams. In: 8th RILEM International Symposium on Fiber Reinforced Concrete BEFIB 2012. Guimaraes, Portugal, pp. 195-196.

[8] Garas VY, Kahn LF, Kurtis KE. (2009) Short-term tensile creep and shrinkage of ultrahigh performance concrete. Cem. Concr. Compos. 31(3):147-152.

[9] Rouse JM, Billington SL. (2007) Creep and Shrinkage of High-Performance FiberReinforced Cementitious Composites. ACI Mats. J. 104(2):129-136.

[10] Barragán, B.E., Zerbino, R.L. (2008) Creep behavior of cracked steel fiber reinforced concrete beams, Proceedings of the 7th International RILEM Symp. on Fiber Reinforced Concrete: Design and Applications (BEFIB 2008), Chenai, RILEM publications, pp. 577-586.

[11] Chanvillard, G., Roque, O. (1999) Behavior of Fiber Reinforced Concrete Cracked Section under Sustained Load. In: Proceedings of the 3rd International Workshop on High Performance Fiber Reinforced Cement Composites, Mainz (Germany), RILEM Publications, pp. 239-250.

[12] Granju, J.L., Rossi, P., Chanvillard, G. et al (2000) Delayed Behavior of Cracked SFRC Beams. In: Proceedings of the Fifth International RILEM Symp. on Fiber Reinforced Concrete (BEFIB 2000), Lyon, France, RILEM Publications, pp. 511-520.

[13] Mackay, J. (2002) Behavior of Steel and Synthetic Fiber Reinforced Concrete under Flexural Creep Loading, MSc Thesis, Dalhousie University, Canada.

[14] Bast, T., Eder, A., Kusterle, W., "Kriechversuche an Kunststoffmakrofaserbetonen Untersuchungen zum Langzeitverhalten von Faserbetonen unter 
Biegezugbeanspruchung - ein Zwischenbericht", Faserbeton Beiträge zum qq. Vilser Baustofftag, pp. 32-35, 2007.

[15] Zerbino R.L., Barragán B.E. (2012) Long-Term Behavior of Cracked Steel FiberReinforced Concrete Beams under Sustained Loading. ACI Mat. J. 109(2):215-224.

[16] Arango SE, Serna P, Martí-Vargas J, García-Taengua E. (2012) A Test Method to Characterize Flexural Creep Behaviour of Pre-cracked FRC Specimens. Exp. Mech. 52(8):1067-1078.

[17] European Committee for Standardization (2007). European Standard EN 14651:2007 "Test method for metallic fiber concrete - Measuring the flexural tensile strength (limit of proportionality (LOP), residual)".

[18] Arango, S.E., "Fluencia a flexión del hormigón reforzado con fibras de acero (SFRC) en estado fisurado" (in Spanish), PhD dissertation, Universitat Politècnica de València, Valencia, Spain, 2010.

[19] Montgomery, D. (2005) Design and Analysis of Experiments, John Wiley \& Sons, Inc., New York, 643 pp.

[20] Hair, F., Black, W., Babin, B., Anderson, R. (2009) Multivariate Data Analysis, Prentice Hall, 816 pp.

[21] Draper, N., Smith, H. (1981) Applied Regression Analysis, John Wiley \& Sons, New York.

[22] Di Prisco, M., Plizzari, G. and Vandewalle, L. (2009) Fiber reinforced concrete: new design perspectives. Mater. Struct. 42(9):1261-1281.

[23] Torrijos M.C., Barragán B.E., Zerbino R.L. (2010) Placing conditions, mesostructural characteristics and post-cracking response of fiber reinforced self-compacting concretes. Constr. Build. Mater. 24(6):1078-1085. 